\title{
ESTUDO DAS REPERCUSSÕES DO PROGRAMA RESIDÊNCIA PEDAGÓGICA NA FORMAÇÃO DE PROFESSORES DE MATEMÁTICA
}

Douglas da Silva TINTI Universidade Federal de Ouro PretoUFOP

Ouro Preto, Minas Gerais - Brasil tinti@ufop.edu.br https://orcid.org/0000-0001-8332-5414

José Fernandes da SILVA Instituto Federal de Educação, Ciência e Tecnologia de Minas Gerais IFMG São João Evangelista, Minas Gerais - Brasil jose.fernandes@ifmg.edu.br https://orcid.org/0000-0002-5798-5379

RESUMO: O presente artigo tem por objetivo analisar as repercussões do Programa Residência Pedagógica - PRP na formação de professores de Matemática. Para tanto, realizou-se uma metassíntese qualitativa a partir de 14 estudos apresentados no XIII Encontro Nacional de Educação Matemática. Com vistas a aprofundar a análise das repercussões, os estudos foram agrupados em cinco categorias, a saber: práticas inovadoras; reflexões sobre o PRP; contribuições para a formação inicial do professor de Matemática; aproximação com a escola da Educação Básica e formação e integração dos envolvidos no PRP. Os resultados permitiram compreender que as repercussões identificadas decorrem das características do PRP, enquanto Política Pública de formação. Desse modo, as repercussões apresentadas são oriundas da centralidade do Programa (formação de professores), que foi dinamizada em regime de parceria entre universidade e escola, mobilizando processos de inserção, imersão e de regência no contexto escolar.

PALAVRAS-CHAVE: Residência Pedagógica, Formação de Professores de Matemática, Políticas Públicas, Educação Matemática. 


\title{
STUDY OF THE REPERCUSSIONS OF THE PEDAGOGICAL RESIDENCY PROGRAM IN THE FORMATION OF MATHEMATICS TEACHERS
}

\begin{abstract}
The aim of this article is to analyze the repercussions of the Pedagogical Residency Program - PRP in the formation of Mathematics teachers. To this end, a qualitative metasynthesis was carried out based on 14 studies presented at the XIII National Meeting on Mathematical Education. In order to deepen the analysis of the repercussions, the studies were grouped into five categories, namely: innovative practices; reflections on the PRP; contributions to the initial training of the mathematics teacher; approach to the Basic Education school and training and integration of those involved in the PRP. The results made it possible to understand that the repercussions identified result from the characteristics of the PRP, as a Public Policy of teacher formation. Hence, the repercussions presented arise from the centrality of the Program (teacher formation), which was enabled by way of a partnership regime between university and school, mobilizing processes of insertion, immersion and conducting in the school context.
\end{abstract}

KEYWORDS: Pedagogical Residency, Mathematics Teacher Formation, Public Policies, Mathematical Education.

\section{ESTUDIO DE LAS REPERCUSIONES DEL PROGRAMA DE RESIDENCIA PEDAGÓGICA EN LA FORMACIÓN DE PROFESORES DE MATEMÁTICAS}

RESUMEN: El presente artículo tiene por objetivo analizar las repercusiones del Programa Residencia Pedagógica - PRP en la formación de profesores de Matemática. Para ello, se realizó una metasíntesis cualitativa a partir de 14 estudios presentados en el XIII Encuentro Nacional de Educación Matemática. Con vistas a ahondar el análisis de las repercusiones, los estudios fueron agrupados en cinco categorías, a saber: prácticas innovadoras; reflexiones sobre el PRP; contribuciones para la formación inicial del profesor de matemática; aproximación con la escuela de la Educación Básica y formación e integración de los involucrados en el PRP. Los resultados permitieron comprender que las repercusiones identificadas derivan de las características del PRP, en cuanto Política Pública de formación. De ese modo, las repercusiones presentadas resultan de la centralidad del Programa (formación de profesores), que fue dinamizada en régimen de convenio entre universidad y escuela, movilizando procesos de inserción, inmersión y de dirección en el contexto escolar.

PALABRAS-ClAVE: Residencia Pedagógica, Formación de Profesores de Matemática, Políticas Públicas, Educación Matemática. 


\section{Introdução}

Diante de um mundo em constante transformação, é cada vez maior o número de pesquisadores que se dedicam a investigar a formação de professores, em especial a de professores de Matemática. O conjunto de mudanças que ocorrem reiteradamente no contexto das sociedades apresenta constantes desafios na construção de currículos para a formação dos novos mestres. Um dos exemplos é a dicotomia existente entre as práticas tecnológicas das crianças e jovens e as práticas presentes nas aulas de Matemática (SILVA, 2018). A dissociação entre teoria e prática é um exemplo clássico do divórcio entre as licenciaturas e as escolas da Educação Básica.

Esse cenário não é exclusividade do Brasil, haja vista que diferentes países enfrentam dificuldades com a falta de diálogo entre a formação matemática e a formação pedagógica (VAILLANT, 2013). Esse, entre outros desafios que se descortinam frente à formação inicial de professores, nos faz refletir sobre a necessidade de tomada de ações para o enfrentamento das dificuldades encontradas. Com vista a minimizar tais desafios, reiteramos o papel das políticas públicas que visam aproximar os futuros professores da realidade escolar, pois ao entrar na carreira profissional estes deparam com situações diversas para as quais nem sempre foram preparados (TINTI; MANRIQUE, 2019).

Tal fato tem chamado a atenção de diferentes organismos, em especial, a Organização das Nações Unidas para a Educação, Ciência e Cultura - UNESCO, que, em 2012, apontou que as sociedades modernas dependem de instituições sólidas, em especial, aquelas que formam os professores, pois estes, necessitam articular conteúdos, valores, culturas e práticas sociais em prol da formação intelectual dos estudantes. Dessa forma, percebe-se a emergência de educadores autônomos e capazes de gerenciar seu próprio processo de aprendizagem (XIMENES-ROCHA; FIORENTINI, 2018).

Igualmente, Gatti (2019), destaca que diferentes organizações governamentais e não-governamentais têm apontado a necessidade de refletir sobre a atratividade da carreira docente, elevação da qualidade das licenciaturas e valorização do campo profissional. Sendo assim, o desenvolvimento de novas políticas públicas para a formação de professores é fundamental. Por outro lado, investigar e discutir as políticasjá existentes faz-se necessário, pois estas culminam em repercussões nos cursos de formação, os quais institucionalizam conhecimentos, práticas e competências que devem ter os futuros professores (SILVA, 2017). Como exemplo de política pública destinada à formação de professores, temos o recém criado Programa Residência Pedagógica - PRP.

Neste sentido, o presente artigo tem como objetivo analisar as repercussões do Programa Residência Pedagógica - PRP na formação de professores de Matemática.

\section{O Programa Residência Pedagógica e a formação de professores de Matemática}

No que tange ao programa citado, pode-se afirmar que o Brasil tem poucas experiências com projetos desta natureza. Entre as iniciativas, destacam-se dois projetos sendo, o primeiro deles, um programa gestado na Universidade Federal de São Paulo - Unifesp, criado em 2009 no âmbito do Curso de Pedagogia (POLADIAN, 2014). O outro trata-se de uma experiência desenvolvida pelo Colégio Pedro II, que, em 2012, iniciou o trabalho, promovendo a Residência Pedagógica nas seguintes áreas: I) Desenho Geométrico e Matemática; II) Biologia, Física e Química; III) Português e Inglês; IV) Geografia e História; V) Filosofia e Sociologia; VI) Artes, Educação Física e Música; e VII) Anos Iniciais do Ensino Fundamental e Educação Infantil (GUEDES, 2018). 
Contudo, em 2017, o Ministério da Educação - MEC anunciou que implantaria o PRP a nível nacional, como forma de modernização do Programa Institucional de Bolsas de Iniciação à Docência - Pibid. Essa decisão gerou debates e manifestações, uma vez que o Pibid se constituía como uma política consolidada e com importantes repercussões no âmbito da Educação Básica.

Instituído pela Portaria No 38, de 28 de fevereiro de 2018, pela Coordenação de Aperfeiçoamento de Pessoal de Nível Superior - Capes, o PRP apresentou como finalidade central apoiar as instituições formadoras no desenvolvimento de propostas que estimulassem a promoção da relação teoria e prática na formação de futuros professores matriculados na segunda metade do curso. Sua primeira edição foi lançada no Edital 06/ 2018/CAPES, tendo como objetivo principal a implementação de projetos institucionais com perspectivas de inovação e articulação entre teoria e prática nos cursos de licenciaturas envolvidos. Além do exposto, o PRP, em sua primeira edição, colocou como prioridades:

- Fortalecer, ampliar e consolidar a relação entre a IES e a escola, promovendo sinergia entre a entidade que forma e a que recebe o egresso da licenciatura e estimulando o protagonismo das redes de ensino na formação de professores;

- Conhecer, através de um levantamento de dados, a realidade educacional das escolas parcerias, bem como suas expectativas no desenvolvimento das ações conjuntas que envolvem a Residência Pedagógica e o Estágio Supervisionado, no âmbito das Licenciaturas;

- Promover estudos e reflexões para elaboração de um plano de ações que envolva os residentes, os preceptores, as escolas parceiras, os gestores, coordenadores de área e os docentes das licenciaturas;

- Promover a imersão dos licenciandos nas escolas campo, visando o reconhecimento de seu campo de atuação, bem como a realização de intervenções no processo de ensino e aprendizagem;

- Promover discussões sobre a adequação dos currículos e propostas pedagógicas dos cursos de formação inicial de professores da educação básica às orientações da Base Nacional Comum Curricular (BNCC) e;

- Ampliar as reflexões, em âmbito institucional, sobre a formação docente, tendo como foco a valorização da carreira (BRASIL, 2018).

Visando alcançar os objetivos citados, o PRP se configura conforme Figura 1: 
Figura 1 - Configuração do Projeto Institucional do PRP.

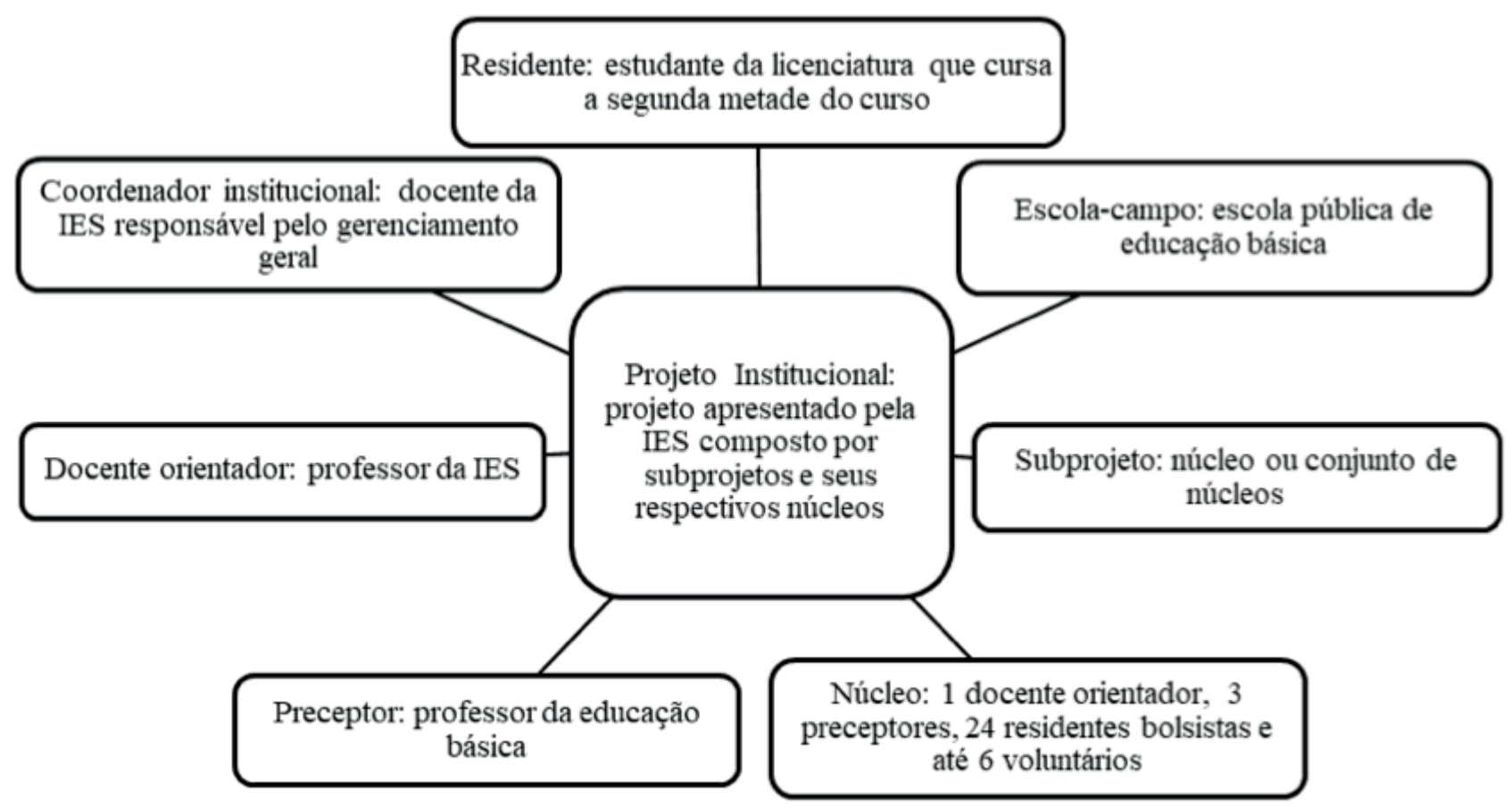

Fonte: Elaborado pelos autores a prtir do Edital CAPES 06/2018.

No que concerne às etapas de implantação o PRP se estrutura em três fases, a saber:

Figura 2 - Módulos de aproximação entre futuros professores e escolas-campo

\section{Ambientação}

Fase de conhecimento da escola

\section{Imersão}

Fase de experimentação pedagógica supervisionada

\section{Regência}

Fase de planejamento, execução e avaliação de aulas

Fonte: Elaborado pelos autores a partir do Edital CAPES 06/2018.

Diante do exposto, a presença desta nova política pública, no seio das licenciaturas, demanda reflexões sobre as práticas dos atores envolvidos. Em outras palavras:

As práticas educativas dos formadores, e futuramente dos que estão se formando como professores, pedem novas compreensões, novas posturas relacionais e novas didáticas para as atividades nos 
ambientes escolares e na construção de relações pedagógicas mais efetivas em sua significação. (GATTlet al., 2019, p.38).

Tal perspectiva tem sido uma constante na literatura que discute a formação do professor de Matemática, em especial os estudos do pesquisador português João Pedro da Ponte que trazem as seguintes reflexões:

Que objetivos se devem estabelecer neste campo na formação inicial de professores? Como atender ao lado pessoal do professor e favorecer o seu desenvolvimento com vista ao exercício da profissão? Que objetivos de formação decorrem da necessidade do professor se tornar membro ativo da sua escola e da sua comunidade profissional? (PONTE, 2002, p.1).

O autor é enfático em citar que formar professores deve ser diferente de formar matemáticos puros. Nesse sentido, é fundamental que as licenciaturas alicercem seus projetos pedagógicos numa perspectiva de formação integral que para Ponte (2002) devem atentar-seàs seguintes dimensões:

I) Formação pessoal, social e cultural dos futuros docentes-essadimensão da formação não se faz presente nas Licenciaturas em Matemática. As causas de evasão dos cursos de Licenciatura em Matemática residem no fato de que para as instituições formadoras o futuro professor já chega com as formações pessoais, que envolvem as dimensões do indivíduo enquanto pessoa, membro da sociedade e de grupos sociais, prontas. Entretanto, é fato que nem todos os licenciandos adquirem essas formações no contexto familiar e/ou no decorrer da Educação Básica. Para Ponte (2002):

A formação nestes campos pode favorecer o desenvolvimento de capacidades de reflexão, autonomia, cooperação e participação, a interiorização de valores deontológicos, as capacidades de percepção de princípios, de relação interpessoal e de abertura às diversas formas da cultura contemporânea, todos eles capacidades e valores essenciais ao exercício da profissão. (PONTE, 2002, p.2).

Sendo assim, essa deveria ser a primeira dimensão formativaadotada pelas instituições formadoras.

II) Formação científica, tecnológica, técnica ou artística na respectiva especialidade - Nessadimensão, Ponte (2002) ressalta a necessidade de o professor de Matemática ter os conhecimentos dos conteúdos específicos. Nesse sentido, "sem dominar, com um elevado grau de competência, os conteúdos que é suposto ensinar, o professor não pode exercer de modo adequado a sua função profissional" (PONTE, 2002, p.2).

III) Formação no domínio educacional - dimensão formativa que envolve os elementos essenciais na constituição da profissionalidade docente: conhecimentos pedagógicos, teorias educacionais e investigação sobre a prática.

IV)Formação nas competências de ordem prática - No âmbito dessa formação está presente o "saber fazer". O professor precisa adquirir, em sua formação inicial, a capacidade de levar seus conhecimentos teóricos para as situações concretas. Nesse sentido, o professor leva para sua prática soluções aos desafios próprios e comuns da atividade docente.

V) Formação nas capacidades e atitudes de análise crítica, de inovação e de investigação pedagógica - O professor necessita situar-se como sujeito com capacidades de analisar, criticar, transformar, produzir e resolver problemas. Assim, "o professor não é um mero técnico nem um simples transmissor de conhecimento, mas 
um profissional que tem de ser capaz de identificar os problemas que surgem na sua atividade, procurando construir soluções adequadas." (PONTE, 2002, p.3).

Ponte (2002) destaca, ainda, a importância de a formação inicial de professores dialogar com as questões da atualidade, pois, segundo o autor, a formação profissional necessita alinhar seu discurso com a sociedade e toda sua conjuntura. Defendendo seu ponto de vista, ele afirma:

Se a formação não preparar o jovem professor para se inserir nas escolas que existem, com os seus alunos e as suas culturas profissionais, corre o sério risco de formar inadaptados, professores que, ao assumirem funções, se sentem completamente deslocados e inaptos para desempenhar o seu papel. Muitos deles podem mesmo abandonar o ensino. Se a formação não prepara os novos docentes para a mudança educativa e social, assume-se como mais uma força conservadora e, no fundo, complacente com os problemas existentes. (PONTE, 2002, p.2).

O exposto nos chama a atenção para a complexidade presente na organização dos processos de formação de professores de Matemática. Tal complexidade advém de diferentes vertentes, mas em especial dos desafios concernentes à prática do dia a dia do professor, pois nela ele:

Toma muitas decisões no seu dia a dia, algumas das quais por vezes em momentos bem difíceis. Debate-se com uma infinidade de tarefas e papeis - educador, matemático, produtor de situações de aprendizagem, animador pedagógico, dinamizador de projectos, investigador, etc. Tem de saber usar uma variedade de recursos na concepção de situações de aprendizagem. Conduz e procura aperfeiçoar a sua actividade de ensino. (PONTE, 1994, p.2).

Diante do exposto, necessitamos compreender o professor como sujeito inacabado, pois da prática profissional emergem diferentes demandas que exigem novos olhares para o fazer pedagógico. Deste modo, as formas compartilhadas de atuação (NACARATO, 2011) podem ser importantes alternativas tanto para a formação inicial,quanto para a formação continuada de professores de Matemática.

\section{Percurso metodológico}

Para atender ao objetivo proposto, optamos por analisar os trabalhos apresentados no XIII Encontro Nacional de Educação Matemática (ENEM)'1, que focalizaram experiências com o PRP. A escolha por esta fonte se justifica pelo fato de este ser o evento de maior expressividade e representatividade da Educação Matemática brasileira e, também, pelo fato de ter sido realizado quase 1 ano após a implementação do PRP nas IES brasileiras.

Ao realizarmos uma busca nos anais² do XIII ENEM, considerando o descritor "residência pedagógica", identificamos 14 estudos que versam sobre o PRP. Com os estudos selecionados, foi realizada uma metassíntese qualitativa que, segundo Fiorentini (2013, p. 78), configura-se como:

Uma meta-interpretação que consiste na interpretação do pesquisador sobre as interpretações produzidas por estudos primários, visando produzir uma outra síntese explicativa ou compreensiva sobre um determinado fenômeno ou tema de interesse.

1 Evento realizado no período de 14 a 17 de julho de 2019 em Cuiabá, Mato Grosso, Brasil.

2 Disponível em https://sbemmatogrosso.com.br/xiiienem/anais.php acesso em 01 de agosto de 2020. 
Considerando esse córpus textual, realizamos a leitura na íntegra dos estudos buscando identificar as repercussões reveladas acerca do PRP na Formação de Professores de Matemática. Em posse destas repercussões, realizamos uma categorização dos estudos em cinco categorias, a saber: i) práticas inovadoras;ii) reflexões sobre o PRP;iii) contribuições para a formação inicial do professor de Matemática;iv) aproximação com a escola da Educação Básica; e v) formação e integração dos envolvidos no PRP.

A seguir, apresentaremos um panorama dos estudos, bem como um detalhamento para cada uma das categorias que emergiram dos dados analisados.

\section{Resultados e discussões}

Os 14 estudos analisados estão inseridos no contexto de implementação do PRP decorrente do Edital $\mathrm{n}^{\circ}$ 006/2018/CAPES. Os estudos são oriundos de projetos institucionais de cinco regiões brasileiras, como podemos evidenciar na Tabela 1.

Tabela 1: Distribuição geográfica dos trabalhos analisados

\begin{tabular}{|c|c|c|}
\hline Região da IES & Total & $\%$ \\
\hline Norte & 4 & 28,58 \\
\hline Sul & 4 & 28,58 \\
\hline Sudeste & 3 & 21,42 \\
\hline Nordeste & 2 & 14,28 \\
\hline Centro Oeste & 1 & 7,14 \\
\hline Total & 14 & 100 \\
\hline
\end{tabular}

Fonte: Elaborado pelos autores (2020).

Além de percebermos uma representatividade regional, é importante mencionar que os 14 estudos são produções conjuntas dos diferentes atores que integram o PRP (residentes, preceptores, docentes orientadores e coordenadores institucionais). Esse dado nos revela uma primeira repercussão do PRP: o desenvolvimento de processos investigativos de maneira colaborativa.

Nesse movimento, a análise dos estudos possibilitou identificar outras repercussões. Com vistas a aprofundá-las, optamos por agrupar os estudos em cinco categorias, tal como apresentamos no Quadro 1. 


\section{Quadro 1: Categorias de análise}

\begin{tabular}{|c|c|}
\hline Categoria & Estudos \\
\hline Práticas inovadoras & $\begin{array}{c}\text { Ludvig, Felichak e Tortola (2019); Oliveira et al. } \\
\text { (2019); Silva e Silva (2019);Santos et al. (2019a); } \\
\text { Santos et al. (2019b) }\end{array}$ \\
\hline Reflexões sobre o PRP & $\begin{array}{c}\text { Celedonio, Alves e Silva (2019); Bastos e Sousa } \\
\text { (2019); Faustino et al. (2019); Zampieri, Sousa e } \\
\text { Gama (2019) }\end{array}$ \\
\hline $\begin{array}{c}\text { Contribuições para a formação inicial do } \\
\text { professor de Matemática }\end{array}$ & $\begin{array}{c}\text { Prestes et al. (2019); Mittelstädtet al. (2019) } \\
\text { Aproximação com a escola da Educação Básica }\end{array}$ \\
\hline Formação e integração dos envolvidos no PRP & Nascimento e Lima (2019); Santana e Barbosa \\
\hline
\end{tabular}

Fonte: elaborado pelos autores (2020).

\section{a) Práticas inovadoras}

Em consonância com o exposto no Edital 06/2018/CAPES, os trabalhos inseridos nesta categoria versam sobre propostas de intervenção pedagógica, assumidas na perspectiva de inovação e articulação entre teoria e prática.

Sendo assim, os estudos de Ludvig, Felichak, Santos et al. (2019a)e Tortola (2019) apresentam reflexões sobre a utilização de jogos nas aulas de Matemática;Silva e Silva (2019) uma proposta integrando a Resolução de Problemas e os Jogos; Oliveira et al. (2019) tomam a música como elemento contextualizador de uma prática e Santos et al. (2019b) apresenta a estruturação de um componente curricular, para uma escola de tempo integral, que contempla diferentes estratégias de ensino.

O estudo de Ludvig, Felichak e Tortola (2019) insere-se no contexto do projeto institucional do PRP3 da Universidade Tecnológica Federal do Paraná, campus Toledo e aborda uma oficina desenvolvida com duas turmas de $3^{\circ}$ ano do Ensino Médio, em uma escola estadual, no período de intervenção pedagógica de Matemática (regência). O jogo escolhido foi "A Batalha do Labirinto", elaborado pelos autores e que visava desenvolver conceitos de Progressões Aritmética e Geométrica. Os autores apontam que, após um levantamento das dificuldades dos alunos e do estudo de diferentes abordagens/estratégias de ensino, optaram pelo jogo por estimular, dentre outras coisas, o agir e o pensar de forma crítica e lúdica.

Para criação do jogo, Ludvig, Felichak e Tortola (2019) apontam que realizaram diferentes estudos, discussões e reflexões com os formadores (preceptores e docentes orientadores) realizando escolhas e tomando decisões didático-pedagógicas. Além do exposto,os citados autores indicam o planejamento realizado como elemento fundamental para o processo de implementação da atividade, a qual foi desenvolvida em duas classes. Em suas palavras: 


\begin{abstract}
Com essa experiência, por exemplo, tivemos a oportunidade de a partir da prévia na universidade fazer melhorias na nossa proposta e, assim, desenvolver uma atividade mais articulada, aproveitando os potenciais do jogo; observamos também a necessidade de modificações a partir do desenvolvimento em turmas e contextos diferentes, nos adaptando às condições e às situações; e, por fim, tivemos que lidar com muitos alunos, que pensam e (re)agem diferente, o que nos sugere como é difícil para um professor trabalhar com atividades diferenciadas e, ao mesmo tempo, manter a ordem e oportunizar aos alunos aprendizagem, mas que, por outro lado, nos mostra como pode ser gratificante a participação e o envolvimento dos alunos e os resultados de sua aprendizagem. (LUDVIG; FELICHAK; TORTOLA, 2019, p. 10)
\end{abstract}

Tal reflexão evidencia a repercussão de uma experiência vivenciada no futuro locus profissional para desenvolvimento de diferentes dimensões formativas (PONTE, 2002). Neste caso, em específico, destacamos aspectos do campo da dimensão prática, bem como a capacidade de realizar análise crítica e proposição de inovação pedagógica.

Coadunando com essa perspectiva, o estudo de Santos et al. (2019a) é decorrente das ações do núcleo Matemática do PRP do Instituto Federal de Rondônia, o qual aborda um projeto com Jogos para os alunos do $7^{\circ}$ ao $9^{\circ}$ ano do Ensino Fundamental de uma Escola Estadualque previa confecção, planejamento e implementação de jogos nas aulas de Matemática. Além disso, os citados autores indicaram que foi possível evidenciar o engajamento dos alunos da escola parceira em todas as etapas do projeto, bem como a contribuição de cada jogo confeccionado para a construção de conceitos matemáticos como, por exemplo, o de equações matemáticas.

Nesse contexto, os autores apontam que esse projeto favoreceu a vivência dos futuros professores ao trabalhar com jogos nas aulas de Matemática, para além da teoria. Entendemos que tal ação repercute, positivamente, para que o futuro professor vivencie práticas de enfrentamento dos desafios e possibilidades inerentes dos processos de ensinar e aprenderMatemática (PONTE, 2002).

Considerando a estrutura dos módulos do PRP (Figura 2) e o foco analítico desta categoria, outros três trabalhos também discorrem sobre práticas pedagógicas de intervenção no contexto escolar.

O primeiro deles trata-se de uma experiência vivenciada no âmbito do PRP da Universidade de Pernambuco, relatada por Silva e Silva (2019). As autoras apontam que, após um período de observação do contexto escolar e considerando que os alunos do $7^{\circ}$ ano do Ensino Fundamental iniciariam os estudos sobre Sistemas de Medidas, optaram por elaborar uma proposta de intervenção (regência) que teve, como ponto de partida, um problema desencadeador de aprendizagem (Resolução de Problemas) e como atividade final (síntese e avaliação da aprendizagem) um jogo de trilha.

Outro estudo é o de Oliveira et al. (2019) que foi desenvolvido no âmbito do PRP do Instituto Federal de Ciência e Tecnologia do Rio de Janeiro - campus Nilópolis, que investigou uma prática desenvolvida em sala de aula, tendo como disparador a relação entre Música e Matemática. Nessa prática, a música foi tomada como contexto problematizador para despertar o interesse dos alunos e mobilizá-los no desenvolvimento de habilidades de coleta, análise e interpretação de dados. O ponto de partida foi um questionário aplicado aos alunos indagando-os sobre suas preferências musicais. De posse dos dados, forampropostas uma organização e uma análise descritiva das informações coletadas para, posteriormente, explorar a relação Matemática - Música. Os autores indicam que: 


\begin{abstract}
Observou-se que um ambiente diferente dos modelos tradicionais de aula proporciona maior interesse. Pois, para o aluno, o que aparentemente era algo apenas lúdico ou cultural, tornou-se uma aula de Matemática prazerosa, por ter associado elementos do cotidiano ao seu ambiente de sala de aula. Neste caso, potencializada pela música, aspecto cultural muito valorizado nas comunidades carentes da Baixada Fluminense. (OLIVEIRA et al., 2019, p. 9).
\end{abstract}

Entendemos que vivências como a citada é salutar para a promoção, valorização e desenvolvimento da formação social e cultural (PONTE, 2002) de todos os atores envolvidos na prática educativa.

Por fim, Santos et al. (2019b) relatam uma experiência vivenciada por oito residentes do núcleo de Matemática do PRP do Instituto Federal de Educação, Ciência e Tecnologia do Rio Grande do Sul - campus Bento Gonçalves. As atividades foram desenvolvidas em uma escola de tempo integral, cuja parte diversificada constava os seguintes componentes curriculares: "Jogos Matemáticos" e "Matemática". Em função disso, após o período de observação, o grupo do PRP propôs a criação de um novo componente curricular, denominado "Pensamento Matemático", cujo objetivo foi contemplar assuntos do cotidiano, como, por exemplo, a Educação Financeira.

Para a construção do novo componente curricular, os residentes tiveram que realizar ações de planejamento, confecção de materiais, estruturação de um espaço físico para o desenvolvimento das aulas (regência), bem como ações de divulgação das atividades junto aos alunos da escola.

A citada experiência nos remete a um dos principais objetivos propostos pelo PRP, o qual visa o fomento a projetos inovadores que estimulem a articulação entre teoria e prática nos cursos de licenciatura em parceria com as redes públicas de educação básica (BRASIL, 2018).

Diante do exposto, os estudos analisados nesta categoria possibilitaram a identificação de diferentes repercussões para a formação dos futuros professores, que passam pela imersão e experimentação de estratégias de ensino, pelo entendimento da distinção entre o planejado e o desenvolvido, bem como o (re)conhecimento da heterogeneidade presente no contexto escolar.

Além disso, as experiências narradas indicam a potencialidade de processos de formação inicial de professores que tomam o contexto real das escolas públicas e mobilize os docentes a diversificarem estratégias/ abordagens de ensino que contribuam para a construção de conceitos matemáticos e, consequentemente, a melhoria das aprendizagens dos estudantes. Essa perspectiva coaduna com a superação da dicotomia entre teoria e prática que, historicamente, é uma marca dos cursos de formação de professores no Brasil (GATTI et al., 2019).

\title{
b) Reflexões sobre o PRP
}

Considerando que os projetos institucionais no âmbito do PRP tiveram início no segundo semestre de 2018 e o XIII Encontro Nacional de Educação Matemática ocorreu em julho de 2019, os trabalhos inseridos nesta categoria apresentam reflexões sobre o processo e a dinâmica de implementação da citada política pública nas IES.

Celedonio, Alves e Silva (2019) relatam a implementação do PRP na Universidade Federal do Tocantins (UFT) - campus Araguaína. No estudo, detalham as etapas desenvolvidas no $2^{\circ}$ semestre de 2018 e no início de 2019. Além disso, os autores enfatizam que o PRP é uma temática emergente de investigação. 
[...]há muito que investigar a cerca desse novo programa, e pretendemos, contudo, prosseguir na observação e análise quanto suas aplicabilidades e contribuições para as escolas-campo nas quais o programa foi implantado e também aos que estão envolvidos [...] como um todo, residentes, preceptores e coordenadores. (CELEDONIO, ALVES E SILVA, 2019, p. 7)

Além disso, a análise deste trabalho sinaliza que uma das repercussões do PRP para a formação do professor de Matemática tem sido o ato de estruturar ações de intervenção no contexto escolar. Para os autores, o PRP tem oportunizado espaços de planejamento pautados pela colaboração e investigação. Assim, afirmam:

\begin{abstract}
A Residência Pedagógica, ainda, têm contribuído não apenas na construção e organização de saberes docentes a fim de desenvolver bem atividades de ensino em sala de aula, mas no compreender aspectos de caráter subjetivo do próprio funcionamento da escola no que diz respeito à gestão, infraestrutura [...], esporte e lazer e relações humanas que envolvem o sujeito professor. (CELEDONIO; ALVES; SILVA, 2019, p. 8)
\end{abstract}

Ainda, no contexto do mesmo projeto institucional, o trabalho de Bastos e Sousa (2019) também reflete sobre o PRP na UFT, porém focaliza as ações desenvolvidas pelo núcleo Matemática do campus Ji-Paraná. No estudo, os citados autores detalham as etapas desenvolvidas no período de agosto de 2018 a janeiro de 2019. Além de descrever as ações desencadeadas, enfatizam atitudes e processos nos quais os residentes necessitaram se mobilizar para a atuação pedagógica, ou seja, "adequar os conhecimentos adquiridos no processo de formação na licenciatura para a realidade e necessidades da sala de aula" (p. 4) escolhendo "metodologias e estratégias didático-pedagógicas diversificadas para trabalhar as necessidades de diferentes grupos de alunos" (p. 4).

Pelo exposto, e considerando a estruturação (Figura 1) e dinâmica (Figura 2) do PRP, podemos inferir que esse processo não é isolado, mas dialogado e coletivo, indicando um movimento que repercute na formação tanto dos residentes quanto dos preceptores e docentes orientadores. Consideramos que esse processo corrobora com o desenvolvimento das capacidades e atitudes de análise crítica, de inovação e de investigação da prática docente (PONTE, 2002).

Outro aspecto relevante a destacar trata-se da repercussão do fomento (bolsa) do PRP no processo formativo dos residentes. A esse respeito os autores discorrem:

É preciso esclarecer que a bolsa favorece muito a participação dos residentes, pois muitos não conseguiriam arcar com as despesas de deslocamento e até mesmo participação de eventos científicos voltados à Educação e Educação Matemática, que em muitos casos apresentam taxas de inscrição [...] acreditamos que o mesmo se reflete em relação aos professores da educação básica envolvidos com o programa. (BASTOS; SOUSA, 2019, p. 11)

Diante dessa reflexão é importante dizer que, embora se reconheça o impacto na vida dos residentes, este aspecto não tem sido tomado como objeto de investigação. Dos trabalhos analisados apenas o de Bastos e Sousa (2019) apresentou, explicitamente, a importância do fomento para a implementação do PRP.

Em conformidade com a discussão proposta nesta categoria, o PRP na Universidade Federal de Mato Grosso do Sul - campus de Aquidauana, foi objeto de estudo de Faustino et al. (2019) que descreveram as ações desencadeadas para implementação e início das atividades dos residentes nas escolas parceiras. Ao refletirem sobre esse processo os autores indicam: 
Sentimos as dificuldades e desafios vivenciados pela professora tanto em sala de aula quanto na escola, a alegria de perceber que se alcançou a aprendizagem do aluno e a frustração quando isso não acontece. Não temos as mesmas responsabilidades, mas tentamos vivenciar e participar de todas as atividades que ela participa. Aprendemos in loco os diversos conflitos que perpassam a profissão. (FAUSTINO et al., 2019, p. 7).

Diante do exposto, podemos evidenciar repercussões no processo de aprendizagem da docência dos professores de Matemática ao adentrarem no contexto do futuro campo profissional, o qual se constitui num cenário real com todas as nuances e complexidades (PONTE, 2002).

Nesse sentido, para que a preparação do futuro professor para a escola da contemporaneidade ocorra é necessário o investimento no tempo de permanência supervisionada no contexto escolar. Tal fato pode romper com as tradicionais formas de estágios, nas quais o licenciando é mero espectador da prática docente. Diante disso, compreendemos que o componente "tempo" pode ser entendido como um diferencial de programas de indução como o PRP. A esse respeito Faustino et al. (2019) afirmam:

Outro aspecto importante dessa fase é a oportunidade de acompanhar o desenvolvimento do ensino de conteúdos e a aprendizagem dos alunos. No estágio ficamos um tempo muito curto em sala de aula e por isso não conseguimos acompanhar todo o desenrolar de um conteúdo. Na residência acompanhamos a turma durante todo o semestre participando de todas as fases do ensino dos conteúdos, desde quando é iniciado, o andamento, o fechamento e o resultado das avaliações. Isso nos permite perceber os sucessos e insucessos em sala de aula. (FAUSTINO et al., 2019, p. 7).

Faustino et al. (2019) corroboram com o que evidenciamos no estudo de Bastos e Sousa (2019), ou seja, de que o PRP repercute na concepção de formação de professores, primando por uma perspectiva colaborativa (NACARATO, 2011).

Por fim, Zampieri, Sousa e Gama (2019) apresentam um estudo que focalizou como o PRP vem sendo implementado nos cursos de Licenciatura em Matemática da Universidade Federal de São Carlos (UFSCar). Para além de detalharem as ações de implementação, as autoras ressaltam o papel das parcerias, do compartilhamento e da colaboração na formação de professores de Matemática.

Uma repercussão desses pilares nos processos formativos foi a mobilização de processos de reflexão com, na e sobre a prática (COCHRAN-SMITH; LYTLE, 2009).

[...] esperamos que a participação no PRP, tanto para os licenciandos, quanto para os professores da Educação Básica (preceptores) e para nós, professores da universidade, enquanto formadores, propicie uma oportunidade para (re) avaliarmos nossas (futuras) práticas, e que nos permita buscar continuamente uma maior aproximação entre universidade e escola, de modo que possamos modificar nossas posturas, muitas vezes individualistas e rotineiras, para que de fato colaboremos uns com os outros, respeitando e compreendendo as diferenças, buscando problematizar os desafios enfrentados na docência de Matemática e pensando conjuntamente em meios para contorná-los. (ZAMPIERI; SOUSA; GAMA, 2019, p. 6-7)

Além disso, o estudo apresentado por Zampieri, Sousa e Gama (2019) evidencia contribuições de experiências vivenciadas no âmbito do Programa Observatório da Educação (OBEDUC) para a condução do PRP na IES. 


\title{
c) Contribuições para a formação inicial do professor de Matemática
}

Os estudos de Prestes et al. (2019) e Mittelstädtet al. (2019) refletem sobre as ações desenvolvidas pelo núcleo de Matemática do PRP da Universidade Regional Integrada do Alto Uruguai e das Missões (URI) campus de Santo Ângelo.

O primeiro estudo foi constituídoa partir de entrevistas realizadas com cinco residentes do núcleo em questão. Os autores justificam que a escolha por esses residentes, num universo de dezesseis, justifica-se pelo fato de os escolhidosterem participado do Programa Institucional de Bolsa de Iniciação à Docência (PIBID) e estarem há, pelo menos, 12 meses no PRP. Já Mittelstädtet al. (2019) optaram por analisar as entrevistas e os materiais didáticos produzidos pelos dezesseis residentes do núcleo de Matemática do PRP da URI.

Inicialmente, tantoPrestes et al. (2019) quanto Mittelstädtet al. (2019),apresentam o contexto em que está inserido o PRP da URI e indicam que as atividades foram desenvolvidas em duas escolas parceiras e congregaram observações, planejamento de ações didáticas e regência de classe.

\begin{abstract}
Através do Programa de Residência Pedagógica, o residente tem a oportunidade de vivenciar a regência de classe através da intervenção pedagógica, gestão da sala de aula, planejamento e execução das ações pedagógicas, buscando propiciar em nível crescente de desenvolvimento e a autonomia do acadêmico em formação, bem como, estimular a inovação e o cumprimento de todas as atividades de sua futura profissão. (MITTELSTÄDT et al., 2019, p. 7)
\end{abstract}

No tocante a observação, Prestes et al. (2019) sinalizam que essa ação permitiu ao residente observar uma determinada turma de alunos, buscar identificar dificuldades apresentadas por eles, refletir sobre estas à luz de discussões teóricas da área de Educação Matemática para, então, elaborar e implementar uma proposta de trabalho (regência). Nesse sentido, a observação favoreceu o estudo de estratégias de ensino (Resolução de Problemas) bem como a estruturação de uma proposta de intervenção (regência) que contribuísse com a aprendizagem matemática dos alunos das escolas parceiras.

No tocante à regência, Prestes et al. (2019) sinalizam que as ações decorrentes do PRP mobilizaram a tomada de decisão frente às situações oriundas da sala de aula para as quais o residente não havia previsto. Nesse sentido, para os autores, tal movimento corrobora com a construção da autonomia do futuro professor, além de oportunizar o desenvolvimento de suas capacidades reflexivas e de conhecimentos essenciais à atuação profissional.

Além disso, Mittelstädtet al. (2019) indicam que o PRP tem possibilitado um contato maior do futuro professor de Matemática com o contexto escolar e enfatizam o papel do preceptor como fundamental para o desenvolvimento da autonomia, da capacidade crítica e reflexiva, e no estabelecimento de relações entre teoria e prática pelos residentes.

Nesse sentido, os estudos de Prestes et al. (2019) e de Mittelstädtet al. (2019) revelam a potencialidade dos processos formativos situados no contexto escolar e acompanhados integralmente pelos formadores (preceptores e docentes orientadores). Além disso, o estudo sinaliza a repercussão na formação inicial do professor de Matemática, decorrente das ações de observação, planejamento e desenvolvimento de propostas de ensino (regência) planejadas e acompanhadas pelos formadores, sobretudo no que se refere ao desenvolvimento da autonomia e articulação entre teoria e prática.Com relação a isso, Ponte (2002, p.3) 
afirma que "[...] oprofessor não é um mero técnico nem um simples transmissor de conhecimento, mas um profissional que tem de ser capaz de identificar os problemas que surgem na sua actividade, procurando construir soluções adequadas".

\section{d) Aproximação com a escola da Educação Básica}

Os estudos que foram inseridos nesta categoria apresentam reflexões sobre as ações desenvolvidas no movimento de aproximação entre IES e escolas da Educação Básica.

[...] a aproximação entre universidade e escola se constitui em um caminho para a orientação e acompanhamento compartilhado. O que pede passagem é a possibilidade de inserção do licenciando no contexto escolar de forma participativa, atuante e propositiva. O convívio neste espaço amplia a possibilidade de desenvolver propostas e investigações relacionadas ao planejamento, a metodologias e ao próprio conteúdo. Essa imersão do residente no espaço escolar potencializa outros modos de formação que não o da universidade. (SANTANA; BARBOSA, 2019, p. 9)

Tanto o estudo de Nascimento e Lima (2019) quanto o de Santana e Barbosa (2019) fazem menção às experiências de (re)conhecimento do contexto escolar. No entanto, o segundo estudo apresenta um olhar teórico para o desenvolvimento de parcerias entre universidade e escola, fomentadas pelo PRP.

Nascimento e Lima (2019)relatam o processo de inserção dos residentes do PRP do Instituto Federal do Rio de Janeiro (IFRJ) - campus Paracambi, em uma escola municipal e outra estadual. As ações narradas pelos autores pautam-se no movimento de conhecer a realidade escolar: estrutura, funcionamento e dinâmica (TINTI, 2012). Ou seja, para além de observar a sala de aula, os residentes buscaram compreender a dinâmica e o funcionamento de diferentes espaços físicos das escolas, bem como conhecer as ações que são desenvolvidas.

Nesse contexto, as observações realizadas foram importantes para que os residentes pudessem planejar e implementar atividades de regência. Observamos na descrição das ações de regência realizadas, em ambas as escolas, a influência das ações de observação mobilizadas no início do PRP. Para ilustrarmos, lançamos mão de uma constatação indicada por um dos residentes: "Após observar diferentes aulas, pudemos notar como lições que dependiam da interação do aluno criavam maior interesse pelo assunto. No entanto, aulas expositivas geravam um maior desinteresse dos alunos" (NASCIMENTO; LIMA, 2019, p. 4). Com vistas a proporcionar um ambiente de interação nas aulas de Matemática, os residentes estruturaram um conjunto de oficinas, denominado por eles de "Feira de Matemática".

Outro ponto a ser destacado é a socialização da experiência entre residentes que foram inseridos na escola estadual e os da escola municipal. Perceber que, mesmo estando localizadas na mesma cidade, as escolas possuem públicos, espaços e dilemas distintos, evidencia a relevância do planejamento de ações de aproximação com a escola antes de planejar ações de intervenção (regência).

Nesse sentido, o estudo de Nascimento e Lima (2019) revela a potencialidade dos processos formativos situados no contexto escolar. Além disso, o estudo sinaliza a repercussão da observação, decorrente da imersão no contexto escolar, no processo formativo de professores de Matemática.

Já o estudo de Santana e Barbosa (2019) reflete sobre as experiências vivenciadas pelos integrantes do subprojeto de Matemática, do PRP da Universidade Estadual de Feira de Santana (UEFS), nos primeiros 
seis meses do PRP. Para tanto, os autores propuseram, a partir dos dados por eles analisados, três grandes eixos da experiência, em que buscaram indícios dos efeitos para a formação, a saber: i) o momento de conhecimento do contexto e cultura da escola; ii) conhecendo a gestão do sistema de ensino, da escola e da sala de aula; iii) experienciando técnicas de ensino, didáticas e metodologias.

Para além da descrição das ações desenvolvidas em cada um dos eixos sinalizados, os autores centraram sua reflexão no estabelecimento de parcerias entre universidade e escola, tal como sinalizado no Edital $n^{\circ}$ 006/2018/CAPES.

Em relação ao movimento de parceria entre universidade e escola, no qual se busca a superação de hierarquias e de valorização dos dois lócus de formação, Santana e Barbosa (2019) sinalizam que, embora se reconheça a potencialidade desta parceria e o papel dos formadores - docente orientador (universidade) e preceptor (escola) - nem sempre os envolvidos no PRP possuem essa percepção e assumem os diferentes papeis que Ihe são legitimados.

\footnotetext{
Com efeito, as condições propiciadas pelo Programa, apesar de serem marcadas por normas e condução de condutas, podem contribuir para a formação inicial e continuada dos sujeitos. Entretanto, o preceptor não se reconhece como sujeito experiente que também pode contribuir para a formação dos residentes e para a construção de atividades inovadoras. A posição assumida pelo preceptor não é de parceria, mas de submissão à figura do representante da universidade. Entretanto, observa-se que a oportunidade de uma formação continuada pode converter-se em objeto de conhecimento e pode produzir outros modos de existir e colocá-los em circulação no social. (SANTANA; BARBOSA, 2019, p. 8)
}

Nesse sentido, o estudo de Santana e Barbosa (2019) revela a potencialidade de processos formativos, mobilizados por parcerias entre universidade e escola, que favoreçam um movimento de reflexão sobre constituição profissional (PONTE, 2002) de cada envolvido - residente, preceptor, docente orientador. Além disso, o estudo sinaliza a repercussão da condução e do desenvolvimento da parceria entre universidade e escola (FOERSTE, 2005) para a formação inicial e continuada de professores. Ou seja, há de se observar a característica dessas parcerias e primar por práticas colaborativas, que superem a lógica de que "universidade forma e a escola acolhe o estudante" (p. 12) e, ainda, que reconheça o papel e a importância de cada uma das instituições formadoras para a formação de professores.

\section{e) Formação e integração dos envolvidos noPRP}

O estudo de Barboza e Ramos (2019) discorre sobre o curso de formação de preceptores, previsto no Edital $\mathrm{n}^{\circ}$ 006/2018/CAPES, desenvolvido pelo PRP do Instituto Federal de Rondônia (IFRO) - campus Cacoal. Tal curso foi desenvolvido via Plataforma Moodle com uma carga horária de 60h, distribuídas em 6 (seis) módulos de $10 \mathrm{~h}$ cada e envolveu os diferentes atores do PRP (residentes; preceptores; e docentes orientadores). Em cada módulo usou-se videoaulas e textos, visando o aprofundamento da temática central estabelecida para cada módulo.

Os autores sinalizam que um dos focos do curso foipromover a integração das instituições envolvidas (IFRO e escolas da Educação Básica). No âmbito desse curso, as interações ocorrerão por meio de fóruns de discussão em ambiente virtual. Nesse sentido, o estudo de Barboza e Ramos (2019) pautou-se nas interações realizadas no primeiro módulo do curso, em que os participantes necessitavam relatar uma experiência escolar (de ensinar ou aprender) enfatizando as dificuldades e refletir sobre elas. Os autores indicam que nessa atividade 
houve novecentos e oitenta e cinco interações entre os 28 participantes do curso de formação, nas quais foram evidenciadas experiências marcadas por dificuldades e por ações exitosas.

Dentre as dificuldades, os autores destacam que foram compartilhadas aquelas relacionadas a ensinar um determinado conteúdo matemático e o processo da compreensão dos alunos. A socialização de tais dificuldades sinaliza uma repercussão no trabalho conjunto e colaborativo a ser desenvolvido nas escolas. Ou seja, revelar e conhecer as dificuldades dos residentes possibilita aos formadores (preceptor e docente orientador) planejarem ações que minimizem o "choque com a realidade" (SILVA, 1997), uma vez que a inserção no contexto escolar faz emergir situações para as quais, nem sempre, a formação inicial os preparou (TINTI; MANRIQUE, 2019).

Nesse direcionamento, Barboza e Ramos (2019) indicam a colaboração como um elemento importante para a superação das dificuldades apontadas.

Como parte da solução para esse problema, destaque-se o companheirismo entre os acadêmicos e professores formadores, pois nesta seara de comentários sobre a dificuldade [...], os professores formadores fizeram sua interferência apontando que o companheirismo dos acadêmicos estava prevalecendo e que estavam colaborando um com o outro. O caminho a ser percorrido, acreditamos ser esse da colaboração entre os pares, já que o professor não é obrigado a saber de tudo, mas que tem por obrigação buscar soluções seja, com um professor mais experiente, um colega, em livros, vídeos, entre outros recursos. (BARBOSA; RAMOS, 2019, p. 4)

Em função disso, observa-se que as experiências consideradas exitosas, para os participantes do estudo, pautaram-se no trabalho colaborativo entre residente e preceptor, tanto na elaboração de uma proposta de intervenção quanto em sua implementação. Tal fato nos remete às reflexões de Ponte (2002) acerca da compreensão de que "[...]a formação de professores pode ser encarada como um processo de indução numa comunidade de prática e de discurso que tem as suas próprias ferramentas, recursos, ideias partilhadas e debates" (p. 4).

Nesse contexto, compreendemos que a principal repercussão que emerge do estudo de Barbosa e Ramos (2019) foi no processo formativo e de integração dos envolvidos no PRP. Além disso, a análise do estudo revela a potencialidade de processos formativos pautados na colaboração, uma vez que favorecem o diálogo, a socialização de sentimentos e a construção conjunta de alternativas para o enfrentamento dos dilemas que emergem dos processos de ensino e de aprendizagem da Matemática.

\section{Considerações finais}

O objetivo central deste artigo foi o de analisar as repercussões do Programa Residência Pedagógica na formação de professores de Matemática. A partir do movimento meta-analítico, foi possível evidenciar que os resultados apresentados decorrem de quatro importantes características do PRP. Compreendemos que o PRP, enquanto política pública de formação de professores, alicerça-se em alguns pilares. Nesse sentido, o movimento de categorização nos permitiu perceber que os trabalhos analisados enfatizaram quatro deles: os processos de inserção e imersão no contexto escolar; as práticas de regência; a formação de professores; e a parceria entre universidade e escola. Temos clareza de que tais pilares estão interligados, no entanto, optamos por focalizá-los individualmente com vistas a elucidar as repercussões que decorrem deles.

O primeiro pilar diz respeito à inserção e imersão de professores, em diferentes momentos da formação, no lócus profissional. Esse movimento repercutiu positivamente na formação dos futuros professores de 
Matemática e, também de seus formadores (preceptores e docentes orientadores), tal como detalhamos no presente artigo. Nesse contexto de inserção e imersão identificam-se ações que têm como ponto de partida o real contexto escolar, as quais corroboram para o enfrentamento do choque com a realidade da futura prática profissional. A partir dos estudos analisados, há de se considerar que esse movimento não se concretizou em ações pontuais, mas em um processo contínuo, que demandou um maior tempo de permanência na escola. Para que isso fosse possível, destacamos a importância do fomento, visto que possibilita aos futuros professores uma maior dedicação às ações que corroboram com seu processo de aprendizagem da docência.

Além disso, os dados evidenciaram que o processo de ambientação, estudo e reflexão sobre a realidade escolar aliado à compreensão das dificuldades dos estudantes mobilizou diferentes ações que possibilitaram a realização de um planejamento de intervenção diferenciado, tendo como base a socialização e articulação entre teoria e prática.

Em segundo lugar, destacamos um aspecto que julgamos ser central no PRP, ou seja, a regência. Considerando que as diferentes ações decorrentes da fase de imersão repercutem na compreensão da escola como um todoe que isso possibilita um planejamento da ação pedagógica mais focalizada, defendemos que o processo de regência necessita ser compreendido além da exposição de conteúdos. Em outras palavras, é necessário reconhecê-lo numa perspectiva mais ampla que congrega investigação, planejamento, implementação e avaliação.

No tocante a esta compreensão, os estudos analisados indicaram que, no âmbito do PRP, uma prática de regência emerge de um movimento de investigação do contexto escolar e é fruto de um trabalho coletivo e colaborativo entre residentes, docentes orientadores e preceptores. Nesse sentido, foi possível identificar a implementação de projetos de intervenção ancorados em diferentes perspectivas didático-metodológicas do campo da Educação Matemática focalizando aprendizagem de diferentes conceitos matemáticos.

Um pilar que expressa um aspecto mais amplo do PRP seria a formação docente. Os dados analisados indicam que o PRP repercutiu em diferentes dimensões da formação docente, tanto dos residentes quanto de seus formadores (preceptor e docente orientador). Além disso, evidenciamos que o PRP mobilizou ações colaborativas, dialógicas e integrativas na relação com o lócus profissional. Nesse sentido, foi perceptível que, dependendo da forma como o PRP é conduzido na IES, ele pode se constituir em um espaço de formação de formadores, fortalecendo os vínculos de colaboração e de parceria entre universidade e escola.

Por fim, e não menos importante, temos que destacar o papel das parcerias entre universidade e escola. Entendemos que tais parceriasnão podem ser impositivas em que só a IES defina o dinamismo, mas uma parceria centrada na colaboração, no diálogo, no respeito mútuo e na promoção do protagonismo de todos os atores envolvidos.

Contudo, considerando que o PRP é um Programa, relativamente, novo e que ainda há muitas questões a serem investigadas, esperamos que as reflexões aqui apresentadas corroborem e mobilizem novos estudos.

\section{Referências}

BARBOZA, Claudemir Miranda; RAMOS, Arilson. Uma experiência em formação continuada no Ambiente Virtual de Aprendizagem: um caso no Programa de Residência Pedagógica In. XIII ENCONTRO NACIONAL DE EDUCAÇÃO MATEMÁTICA - ENEM. Cuiabá, Mato Grosso, 2019, p. 1-10. Disponível em https://cutt.ly/ KfHcclk. Acesso em 01/08/2020. 
BRASIL. Portaria n. 38, de 28 de fevereiro de 2018 que regulamenta o Programa de Residência Pedagógica, Brasília, DF, 2018. Disponível emhttps://cutt.ly/wfHbhDC. Acesso 01/08/2020.

BRASIL. Edital n. 06/2018 CAPES seleção de projetos para o Programa Residência Pedagógica. Brasília: DF: CAPES, 2018. Disponível em https://cutt.ly/wfHbvOR. Acesso em 02/08/2020.

BASTOS, Ana Fanny Benzi de Oliveira Bastos; SOUSA, Elisandra Rodrigues de. A Residência Pedagógica em Matemática: o início das vivências na sala de aula. In. XIII ENCONTRO NACIONAL DE EDUCAÇÃO MATEMÁTICA - ENEM. Cuiabá, 2019, p. 1-12. Disponível em https://cutt.ly/yfHcbgj. Acesso em 01/08/2020.

CELEDONIO, Patrícia Silvério da Silva; ALVES, Deive Barbosa; SILVA, Gildemberg da Cunha Silva. Residência Pedagógica: novas perspectivas para formação de professores. In. XIII ENCONTRO NACIONAL DE EDUCAÇÃO MATEMÁTICA - ENEM. Cuiabá, Mato Grosso, 2019, p. 1-9. Disponível em https://cutt.ly/UfHcnHa. Acessoem 01/08/2020.

COCHRAN-SMITH, Marilyn; LYTLE, Susan. Inquiry as stance: practitioner research for nextgeneration. New York: TeacherCollege Press, 2009.

ENCONTRO NACIONAL DE EDUCAÇÃO MATEMÁTICA - ENEM, 13, 2019, Cuiabá: SBEM/MT, 2019. Disponível em https://www.sbemmatogrosso.com.br/xiiienem/. Acesso em 01/08/2020.

FOERSTE, Erineu. Parceria na formação de professores. São Paulo: Cortez, 2005

FAUSTINO, Luiza Cordeiro de Andrade Faustino. Ambientando à Residência Pedagógica. In. XIII ENCONTRO NACIONAL DE EDUCAÇÃO MATEMÁTICA - ENEM. Cuiabá, Mato Grosso, 2019, p. 1-10. Disponível em https://cutt.ly/GfHcQfj. Acesso em 01/08/2020.

FIORENTINI, Dario. A Investigação em Educação Matemática desde a perspectiva acadêmica e profissional: desafios e possibilidades de aproximação. Cuadernos de Investigación y Formación en Educación Matemática, v. 8, n. 11, p. 61-82, 2013.

GATTI, Bernardete Angelina; BARRETTO, Elba Siqueira de Sá; ANDRE, Marli Elisa Dalmazo Afonso de; ALMEIDA, Patrícia Cristina Albieri de. Professores do Brasil: novos cenários de formação. Brasília, DF: Unesco, 2019.

GUEDES, Luisa Azevedo. O Programa de Residência Docente do Colégio Pedro II: Escritas de Formação n a área dos Anos Iniciais do Ensino Fundamental. 2018. 161f. Tese (Doutorado em Educação) - Programa de Pós-Graduação em Educação. Universidade Federal do Rio de Janeiro - Rio de Janeiro, 2018.

LUDVIG, Daniela Carolina; Felichak, Danieli;TORTOLA; Emerson. A Batalha do Labirinto: uma experiência por meio do Programa Residência Pedagógica. In. XIII ENCONTRO NACIONAL DE EDUCAÇÃO MATEMÁTICA ENEM. Cuiabá, Mato Grosso, 2019, p. 1-9. Disponível em https://cutt.ly/NfHcWJK. Acesso em 01/08/2020.

MITTELSTÄDT, Patrícia Tais [et al]. A formação do professor de matemática integrantes do Programa Residência Pedagógica numa perspectiva colaborativa e reflexiva. In. XIII ENCONTRO NACIONAL DE EDUCAÇÃO 
MATEMÁTICA - ENEM. Cuiabá, Mato Grosso 2019, p. 1-10. Disponível em https://cutt.ly/rfHcEMX. Acesso em 01/08/2020.

NACARATO, Adair Mendes. A formação do professor de Matemática: práticas e pesquisas. REMATEC, v. 6 , n.9, p. $27-48,2011$

NASCIMENTO, Wellington Andrade do Nascimento; LIMA, Breno Souza Duarte Lima. Residência Pedagógica: o primeiro contato do residente com a escola. In. XIII ENCONTRO NACIONAL DE EDUCAÇÃO MATEMÁTICA - ENEM. Cuiabá, Mato Grosso, 2019, p. 1-7. Disponível em https://cutt.ly/FfHcTpF. Acesso em 01/08/2020.

OLIVEIRA, Valmir Alves de [et al]. A Música na Formação dos Professores de Matemática do Programa Residência Pedagógica. In. XIII ENCONTRO NACIONAL DE EDUCAÇÃO MATEMÁTICA - ENEM. Cuiabá, Mato Grosso, 2019, p. 1-10. Disponível em https://cutt.ly/gfHcYEF. Acesso em 01/08/2020.

POLADIAN, Marina Lopes Pedrosa. Estudo sobre o Programa de Residência Pedagógica da UNIFESP: uma aproximação entre universidade e escola na formação de professores. 2014, 128f. Dissertação (Mestrado em Educação: Psicologia da Educação) - Pontifícia Universidade Católica de São Paulo - São Paulo, 2014.

PONTE, João Pedro da. A vertente profissional da formação inicial de professores de matemática. Educação Matemática em Revista, 11A, 3-8, 2002.

PRESTES, Rosangela Ferreira [et al]. Programa Residência Pedagógica: espaço de produção e aprendizagem de conhecimentos da docência In. XIII ENCONTRO NACIONAL DE EDUCAÇÃO MATEMÁTICA - ENEM. Cuiabá, Mato Grosso, 2019, p. 1-15. Disponível em https://cutt.ly/yfHcITI. Acesso em 01/08/2020.

SANTANA, Flávia Cristina de Macêdo; BARBOSA, Jonei Cerqueira. O Programa Residência Pedagógica/ Subprojeto de Matemática e a relação Universidade e Escola: Resistências E Modos De Subjetivação. In. XIII ENCONTRO NACIONAL DE EDUCAÇÃO MATEMÁTICA - ENEM. Cuiabá, Mato Grosso, 2019, p. 1-15. Disponível em https://cutt.ly/KfHcOBe. Acesso em 01/08/2020.

SANTOS, Lidiane Schuck dos [et al]. Residência Pedagógica: contribuições para a Educação Básica e Superior. In. XIII ENCONTRO NACIONAL DE EDUCAÇÃO MATEMÁTICA - ENEM. Cuiabá, Mato Grosso, 2019b, p. 1-9. Disponível em https://cutt.ly/pfHcPVF. Acesso em 01/08/2020.

SANTOS, Priscila Miranda Engelhardt[et al]. Jogos matemáticos: uma experiência com os alunos do Ensino Fundamental através do Programa Institucional Residência Pedagógica. In. XIII ENCONTRO NACIONAL DE EDUCAÇÃO MATEMÁTICA - ENEM. Cuiabá, Mato Grosso, 2019a, p. 1-10. Disponível em https://cutt.ly/ XfHcSap. Acesso em 01/08/2020.

SILVA, José Fernandes da. Um estudo do Programa de Consolidação das Licenciaturas no contexto da formação inicial de Professores de Matemática. 2017. 253f. Tese (Doutorado em Educação Matemática) - Programa de Pós-Graduação em Educação Matemática. Universidade Anhanguera de São Paulo - São Paulo, 2017.

SILVA, JosenaideApolonia de Oliveira Silva; SILVA, Claudineia Maria Marcelino da Silva. Aprendendo sobre grandezas e unidades de medidas com o uso de jogos: experiências do Programa Residência Pedagógica 
matemática em um $7^{\circ}$ ano. In. XIII ENCONTRO NACIONAL DE EDUCAÇÃO MATEMÁTICA - ENEM. Cuiabá, Mato Grosso, 2019, p. 1-8. Disponível em https://cutt.ly/HfHcDFm. Acesso em 01/08/2020.

SILVA, Maria Celeste Marques da. O primeiro ano de docência: o choque com a realidade. In: ESTRELA, Maria Teresa (Org.) Viver e construir a profissão docente. Portugal: Porto Editora, 1997, p. 51-80.

TINTI, Douglas da Silva. PIBID: um estudo sobre suas contribuições para o processo formativo de alunos de Licenciatura em Matemática da PUC-SP. 2012. 148f. Dissertação (Mestrado em Educação Matemática) - Programa de Estudos Pós-Graduados em Educação Matemática. Pontifícia Universidade Católica de São Paulo - São Paulo, 2012.

TINTI, Douglas da Silva; MANRIQUE, Ana Lúcia. PIBID: Inserção de futuros professores de matemática no ensino escolar com vistas a minimizar o choque com a realidade. Linhas Críticas, v. 25, 20 fev. 2019. Disponível em: https://doi.org/10.26512/lc.v25i0.23110. Acesso em 22/08/2020.

UNESCO.Antecedentes y criterios para la elaboración de políticasdocentes en América Latina y el Caribe. Instituto de Estadística de la UNESCO, Santiago, 2012.

VAILLANT, Denise. Desarrollo profesional, evaluación y políticas docentes en Latinoamérica. 2013. Disponível em http://www.ort.edu.uy/ie/articulos/desarrollo-profesional-evaluacion-y-politicas-docentes-en-latinoamerica. pdf. Acesso em 01/08/2020.

XIMENES-ROCHA, Solange Helena, FIORENTINI, Dario. Formação de professores em comunidades colaborativas no interior da Amazônia. Educação (UFSM), 43(2), 267-284. 2018. Disponível em https://doi. org/10.5902/1984644428842. Acesso em 01/08/2020.

ZAMPIERI, Maria Teresa; SOUSA, Maria do Carmo; GAMA, Renata Prenstteter. Residência Pedagógica na área de Matemática: implementação e expectativas na UFSCAR. In. XIII ENCONTRO NACIONAL DE EDUCAÇÃO MATEMÁTICA - ENEM. Cuiabá, Mato Grosso, 2019, p. 1-9. Disponível em https://cutt.ly/nfHcF4C. Acesso em 01/08/2020

TINTI, D. S.; SILVA, J. F.; Estudo das repercussões do programa residência pedagógica na formação de professores de matemática Formação Docente - Revista Brasileira de Pesquisa sobre Formação de Professores. Belo Horizonte. Vol. 13, n. 25 (p. 151-172) 31 dez. 2020. ISSN:2176-4360. DOI https://doi.org/10.31639/rbpfp.v13i25.404 
